\title{
Thoracic mobility and its relation to pulmonary function and rib-cage deformity in patients with early onset idiopathic scoliosis: a long-term follow-up
}

\author{
Karin Romberg ${ }^{1,2} \cdot$ Monika Fagevik Olsén ${ }^{1,2} \cdot$ Gunilla Kjellby-Wendt $^{1,2} \cdot$ Kerstin Lofdahl Hallerman $^{3,4}$. \\ Aina Danielsson ${ }^{5,6}$
}

Received: 26 November 2018 / Accepted: 11 August 2019 / Published online: 19 February 2020

(c) The Author(s) 2020

\begin{abstract}
Study design A group of adult patients with idiopathic scoliosis, diagnosed before the age of ten, at a mean of 26.5 years after treatment with either brace or surgery during childhood and adolescence attended a clinical follow-up.

Objectives To evaluate the relation between thoracic mobility, rib-cage deformity, and pulmonary function.

Summary of background data Long-term studies of pulmonary function in relation to thoracic mobility after treatment in this patient group have not been published.

Methods A total of 106 patients, 57 braced and 49 operated patients, attended the follow-up. We examined thoracic mobility (range of motion of the thoracic spine, thorax expansion, and breathing movements) and rib-cage deformity (curve size and trunk deformity) as well as pulmonary function, especially total lung capacity (TLC). Respiratory muscle strength was evaluated in a subgroup.

Results Thoracic range of motion was significantly less among the surgically treated patients compared with both the bracetreated and comparison group. Thorax expansion and breathing movements during maximal breathing were significantly reduced in the scoliotic patients compared with the reference values, with no significant differences between the treatment groups. The brace-treated group had better pulmonary function than the operated group, as measured by the TLC, forced vital capacity (FVC), and forced expiratory volume in one second (FEV1) (percentage of predicted values). The respiratory muscle strength was significantly lower only in the surgically treated patients when compared with reference values. The results of a multivariate analysis revealed that the strongest factors explaining TLC percentage of predicted were gender, brace model, and smoking habits.

Conclusions Thoracic mobility was significantly reduced at mean 26.5 years after completed treatment in both brace-treated and surgically treated patients with early onset scoliosis, compared with the reference values, which did not influence TLC as strongly as gender, brace model, and smoking habits.
\end{abstract}

Levels of evidence Level III.

Keywords Breathing movements · Idiopathic scoliosis · Long-term · Thoracic mobility · Pulmonary function

Karin Romberg

karin.romberg@vgregion.se

1 Department of Health and Rehabilitation, Institute of Neuroscience and Physiology, Sahlgrenska Academy, University of Gothenburg, Box 455, 40530 Gothenburg, Sweden

2 Department of Physical Therapy, Sahlgrenska University Hospital, 41345 Gothenburg, Sweden

3 Department of Respiratory Medicine, Department of Internal Medicine and Clinical Nutrition, Institute of Medicine,
Sahlgrenska Academy, University of Gothenburg, Gothenburg, Sweden

4 Department of Respiratory Medicine, Sahlgrenska University Hospital, Gothenburg, Sweden

5 Department of Orthopaedics, Institute of Clinical Sciences, Sahlgrenska Academy, University of Gothenburg, Gothenburg, Sweden

6 Department of Orthopaedics, Sahlgrenska University Hospital, Gothenburg, Sweden 


\section{Introduction}

Long-term studies have shown that, left untreated, patients with early onset of scoliosis run an increased risk for respiratory failure and premature death [1]. This is probably due to restricted lung development before adulthood resulting in lower number of alveoli $[2,3]$ and to altered biomechanics of the rib cage.

Early onset scoliosis that increases to a large curve size also results in chest deformity with ensuing reduced chest and lung volume [4]. Furthermore, the distorted chest is thought to lead to reduced thoracic mobility and increased work of breathing. The treatment of scoliosis with fulltime brace wearing for several years or with fusion of the spine might also contribute to restricted motion of the rib cage. The mobility and muscle endurance of the spine in adult patients treated for scoliosis during childhood and adolescence has been shown to be reduced [5-7]. However, the thoracic mobility and the breathing movements have not been evaluated in these groups of patients, despite the possibility for its evident clinical importance.

Basic pulmonary function has traditionally been measured with spirometry [8]. Other methods exist, but have not been extensively used for scoliosis patients. The respiratory movements consist of abdominal and rib-cage movements [9]. The separate volume changes of the rib cage and abdomen can be measured during breathing, and healthy individuals can breathe with any combination of these locations of breathing [9]. In the sitting position, abdominal breathing dominates, probably because of a more optimal muscle fiber length of the diaphragm leading to a stronger contraction [10], and the rib cage contributes $60 \%$ to total ventilation, compared with $35 \%$ in the supine position.

Thoracic mobility, that is, the mobility of the thoracic spine and the rib cage, is often measured with a kyphometer [11] and with measurement of the degree of thorax expansion during breathing [12-14]. The latter gives a general overview of the maximal range of motion in the upper and the lower part of the rib cage. The measurement of breathing movements [15-17], another way to evaluate the rib-cage mobility, has been available for the past 10 years by use of the Respiratory Movement Measuring Instrument (RMMI). Several studies, with patients with ankylosing spondylitis, after cardiac surgery, and those diagnosed with sensory hyperreactivity, have been published [18-20].

Breathing movements and maximal range of motion in the rib cage are associated with the strength in the respiratory muscles. For evaluation of respiratory muscle strength, noninvasive measurement of the maximal inspiratory pressure (MIP) and the maximal expiratory pressure (MEP) is used [21, 22].
The aim of this study was to evaluate how thoracic mobility, as measured by different methods, and rib-cage deformity relate to pulmonary function in adult patients treated for early onset idiopathic scoliosis during childhood or adolescence. The total lung capacity (TLC), considered the key measurement for establishment of a restrictive deterioration of the ventilatory capacity when performed in a body plethysmograph, was chosen to represent the pulmonary function.

\section{Methods}

\section{Patients}

The Gothenburg Scoliosis Database, which contains information about all patients between 1966 and 1994 with scoliosis at the Department of Orthopaedics at the Sahlgrenska University Hospital, Gothenburg, Sweden, was used to identify the study population. This met the following criteria: (1) diagnosis of idiopathic scoliosis before the age of 10 years; (2) treatment with either a brace (for at least 6 months) or with surgery; (3) no other related disorders or spine anomalies; and (4) $>10$ years since maturity or surgical procedure. Details about the treatments have been published earlier (https://doi.org/10.1016/j.jspd.2015.07.007).

The original series of patients consisted of 179 consecutive patients, of which 106 completed this study (Fig. 1). Fifty-seven patients were brace-treated only until maturity, until 1974 with a Milwaukee brace (in 24 patients) and thereafter a Boston brace (33 patients). All together, 49 patients were surgically treated and 31 of those were initially braced but operated before maturity due to curve progression. A further six patients, with a remaining significant curve at maturity or curve progression after maturity, were operated shortly after maturity, before the age of 22 years. The surgical procedure was performed with Harrington instrumentation until 1995 (used in 46 patients) and thereafter with the Isola system (in three patients).

\section{Examination of the curve, pulmonary function, and smoking habits}

All patients underwent measurement of rib-cage deformity including trunk deformity by use of Bunnell scoliometer [23]. Full standing posterior-anterior digital roentgenograms were performed at the follow-up, and curve size was measured using the Cobb method [24].

Spirometry by a pressure-differences method (Jaeger MasterScope) was used to measure forced vital capacity $(\mathrm{FVC})$ and forced expiratory volume in one second $\left(\mathrm{FEV}_{1}\right)$. TLC was measured with a body plethysmograph. Values are presented as the percentage of predicted values related 
Fig. 1 Flow chart of included patients

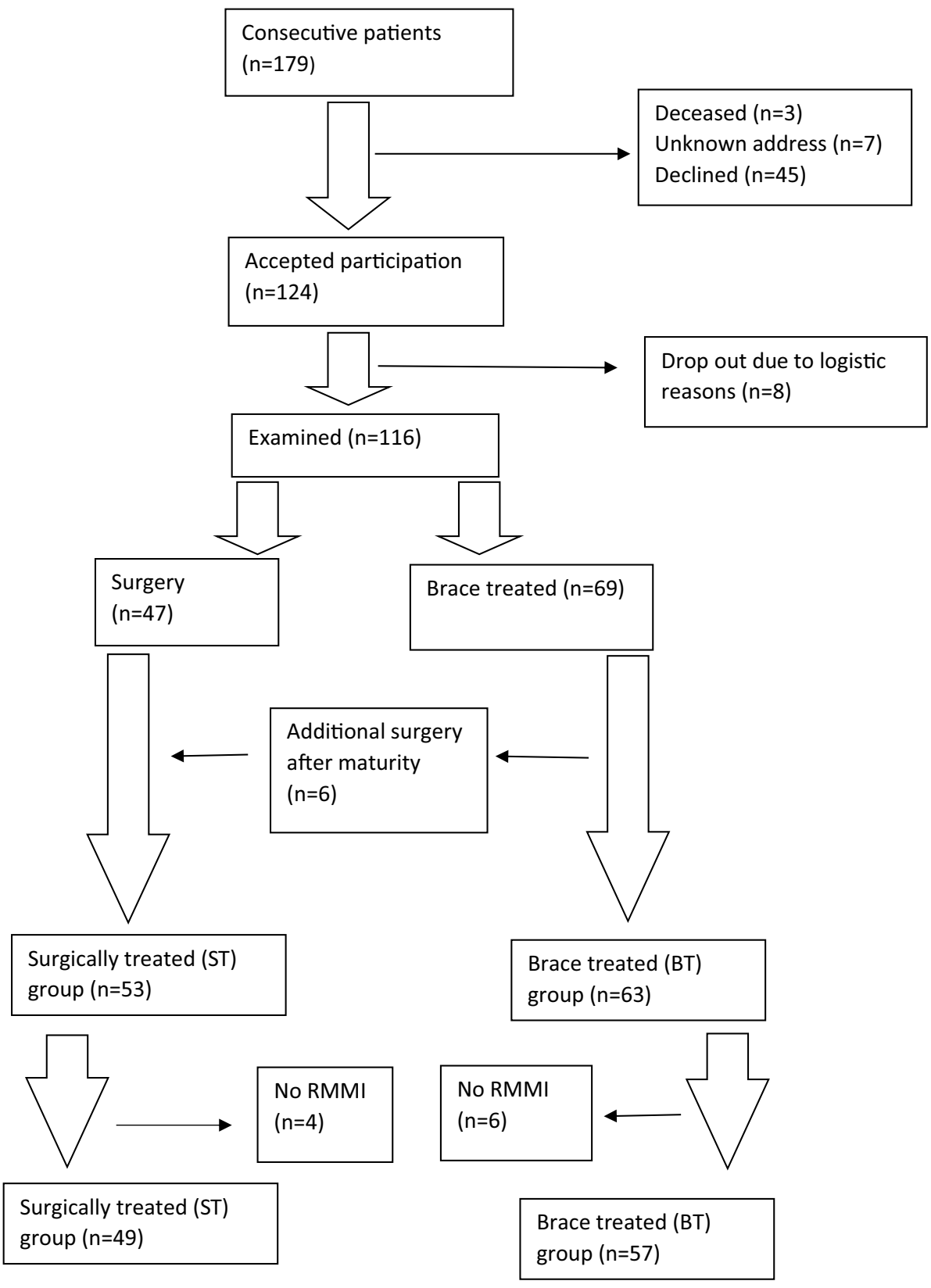

to age, height, and gender according to Quanjer et al. [8] for FVC and $\mathrm{FEV}_{1}$ and Quanjer et al. [25] for TLC and corrected to loss of height due to scoliosis according to Lind [26].

The patients were asked about smoking habits, and they were thereafter classified into either never smokers or current/ex-smokers ("ever-smokers").

\section{Examination of thoracic mobility with three different methods}

Three different methods were used for evaluation of the different aspects of the function of the thoracic cage: (1) range of motion of the thoracic spine [11]; (2) expansion of the thorax during breathing [13, 14]; and (3) breathing movements-respiratory movement measuring instrument (RMMI) [27-30]. The methods are described in Table 1 and Figs. 2, 3, 4, 5, 6.

\section{Examination of respiratory muscle strength}

The respiratory muscle strength was examined in a subgroup of 33 patients (of the 106 in the original study group) three to 5 years after the initial follow-up. The method is described in Table 1 [22]. The mean curve size at follow-up 
Table 1 Methods for evaluation of thoracic mobility and respiratory muscle strength

Thoracic mobility

1. Range of motion of the thoracic spine (Fig. 2)

Technique: Performed in standing position from a point between the spinous processes of T2-T3 and from a second point between T11 and T12 by use of a Debrunner kyphometer [11]

Reference values: A randomly selected age- and gender-matched control group of 100 persons was previously collected through the National

Population Registry [5]. These individuals had no history of scoliosis, which was controlled by use of a Bunell scoliometer [23]

2. Expansion of the thorax during breathing (Fig. 3)

Technique: Measurement of the ability for the chest cage to expand the thorax, "Thorax expansion," was measured twice with a measuring tape as the circumference of the thoracic cage, at the level of the xiphoid process and at the level of the fourth rib. The expansion was calculated as the difference between maximum expiration and maximum inspiration

The subjects were standing with their hands placed on their heads and were instructed to first make as large an inhalation as possible and "make themselves as big as possible" and then to exhale maximally and "make themselves as small as possible" [13, 14]

Reference values: Results were compared with age-related reference values, measured at the level of the xiphoid process [13]. No reference values exist for the level of fourth rib

3. Breathing movements: Respiratory Movement Measuring Instrument (RMMI) (Figs. 4 and 5)

Technique: The changes in the anterior-posterior diameter of the thorax during deep breathing were performed with the RMMI in a supine position on a treatment bench [27]. The RMMI consists of a mobile rack with six laser diodes in three pairs, adjustable to the length of each participant's torso. The accuracy of the six laser distance sensors is $0.0003 \mathrm{~mm}$. These diodes are arranged bilaterally at the level medial to each individual's armpit folds, and lateral to the xiphoid process and the umbilicus, and can, therefore, register the amplitude of the breathing movements. These signals were converted from analog to digital by the data acquisition system and transmitted to a computer program [27-30]. The reliability and validity of RMMI has been evaluated and it was found to be a reliable instrument for clinical practice and research [29, 30]. The breathing movements have been evaluated and considered symmetrical and did not change significantly with increasing age [27]

The measurements of each individual in the study group were adjusted to the direction of the scoliosis, i.e., either the convex or the concave side Breathing movements were analyzed as the sum of movements on both sides on all six positions and on the upper thoracic and abdominal positions

Reference values: Values were compared with the mean values of the corresponding group of healthy individuals of similar age and gender [27]

4. Respiratory muscle strength (Fig. 6)

Technique: The maximal inspiratory pressure (MIP) and maximal expiratory pressure (MEP) were measured in the sitting position [22]. Each patient performed three MIP and three MEP tests and the tests with the highest scores were recorded and analyzed to the results of the comparison group

Reference values: An age-, gender- and BMI (body mass index)-matched control group was recruited. This consisted of a convenience sample of 40 healthy individuals, $25 \%$ of them ever-smokers, with no history of scoliosis and with less than $5^{\circ}$ of trunk rotation when examined with a Bunell scoliometer [23]

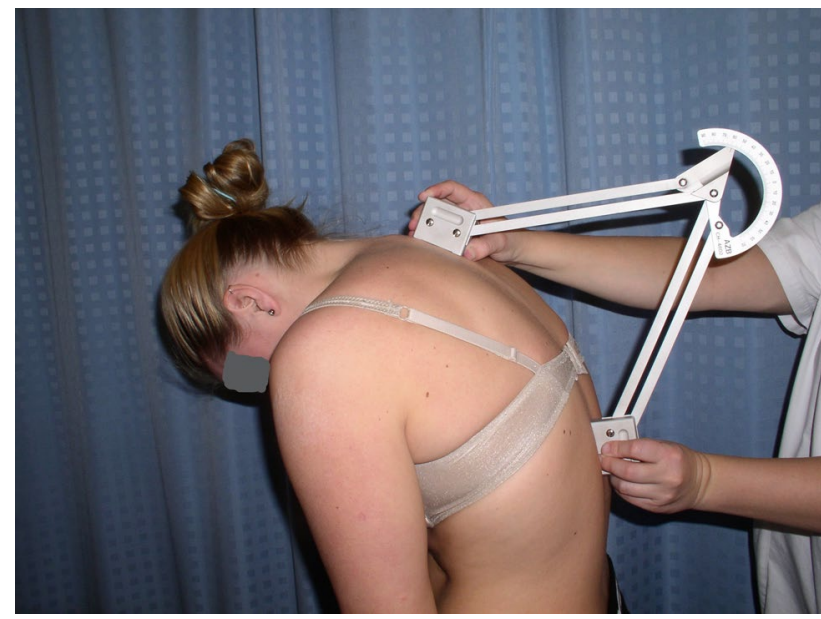

Fig. 2 Total thoracic range of motion measured with a Debrunner kyphometer

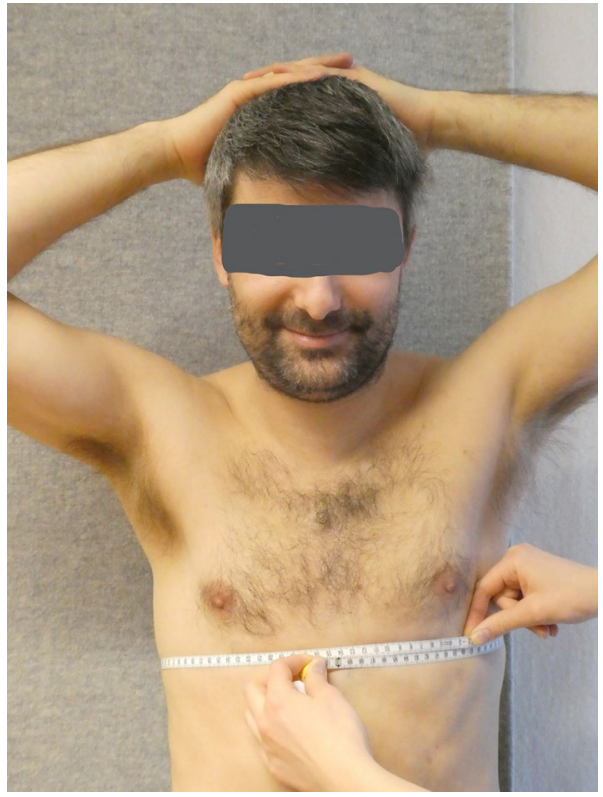

Fig. 3 Measurement of thorax expansion at the level of the xiphoid process 


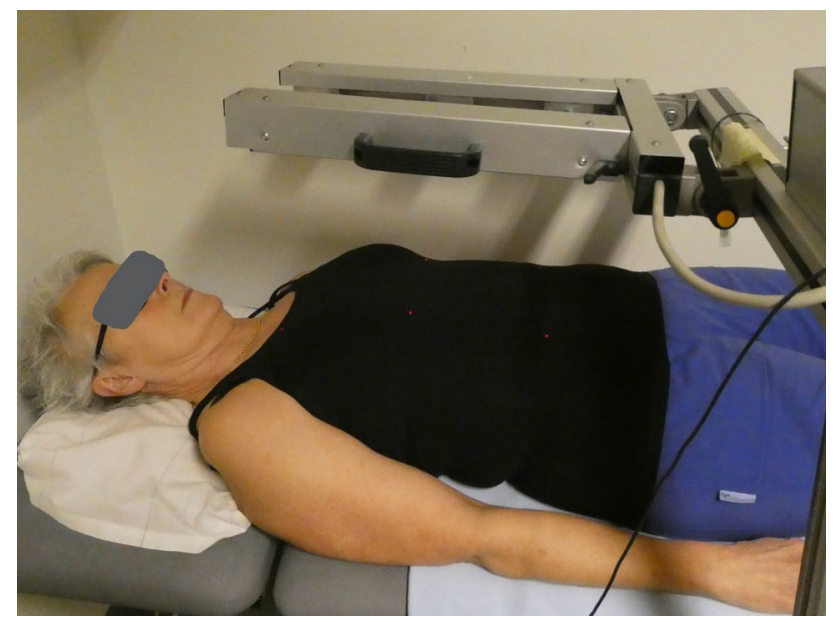

Fig. 4 Respiratory movement measuring instrument (RMMI) was similar in these two groups, mean $37.2^{\circ}$ (brace-treated [BT] group, $36.1^{\circ}, n=16$; and surgically treated [ST] group, $\left.38^{\circ}, n=17 ; p=0.6\right)$. The number of ever-smokers was 11 (33.3\%) (BT group, 7 [43\%]; ST group 4 [23\%]).

\section{Statistical methods}

Distributions of variables are given as means, standard deviations, and ranges. For comparison between the two groups and the groups versus normal/reference values, the Mann-Whitney nonparametric $U$ test was used. For comparison of proportions between two groups, Fisher exact test was used.

Spearman rank correlation coefficient was used for correlation analysis. Correlation was defined as follows: little, if any $\left(r_{\mathrm{s}}<0.25\right)$, low $\left(r_{\mathrm{s}}=0.26-0.49\right)$, moderate $\left(r_{\mathrm{s}}=0.50-0.69\right)$, high $\left(r_{\mathrm{s}}=0.70-0.89\right)$, and very high $\left(r_{\mathrm{s}}=0.9-1.00\right)$ [31].

A univariate and multivariate analysis was made based on variables possible to explain TLC percent predicted. All significance tests were two-tailed and were conducted at the $5 \%$ significance level.

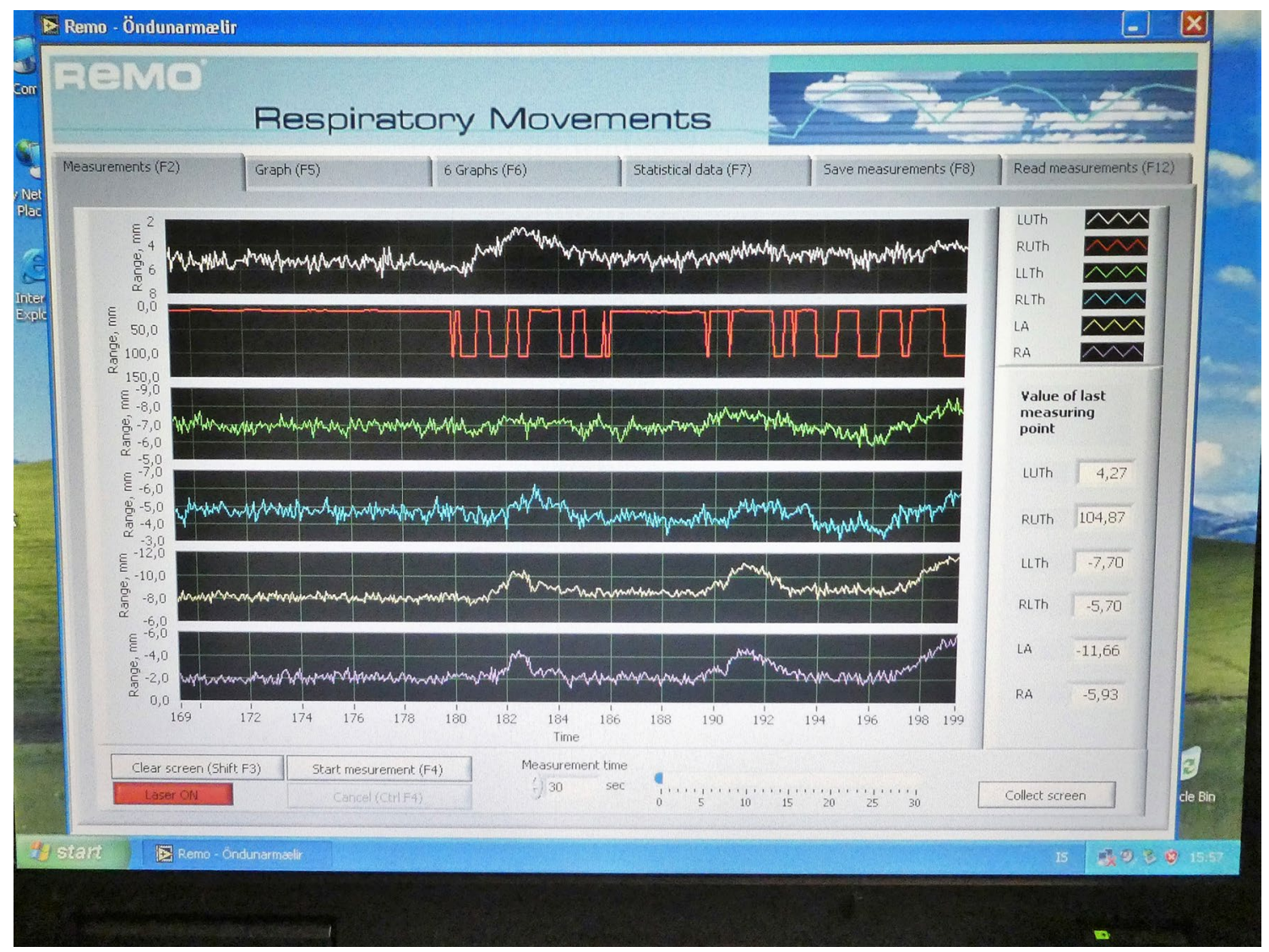

Fig. 5 Screen picture of the measurement performed with the RMMI. The results of the movements measured at the six measuring points: left and right upper thoracic, left and right lower thoracic, and left and right abdominal 


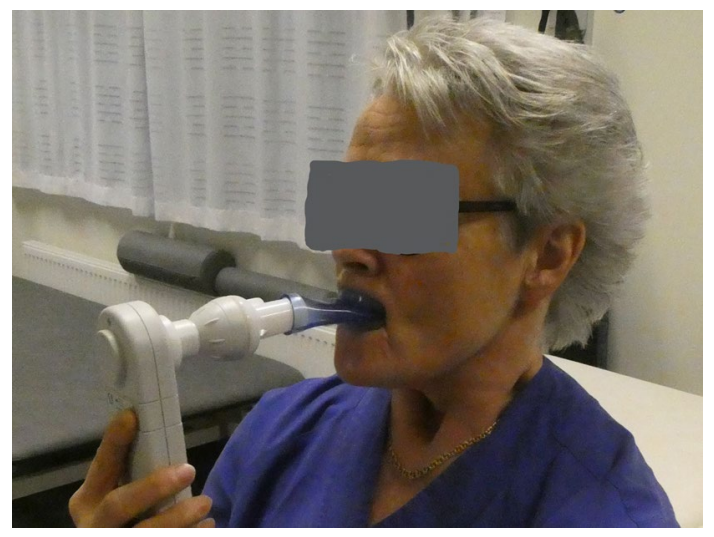

Fig. 6 Maximal inspiratory pressure (MIP) and the maximal expiratory pressure (MEP) measured in the sitting position

\section{Results of the univariate analysis}

\section{Description of demographic data, curve size, trunk deformity, pulmonary function, and smoking habits}

Table 2 depicts information about the study group. Mean age at diagnosis and at the present study was 7 years and 41.7 years, respectively, with no significant difference between the braced and the operated patients. Curve size before treatment was significantly larger in the operated group compared with the braced group $\left(57^{\circ}\right.$ vs. $\left.28^{\circ}\right)$ and 35 patients (all in the ST group) had a curve size of $50^{\circ}$ or more. Curve size at present follow-up did not differ significantly between the groups ( $\mathrm{ST} 37^{\circ}$ and $\mathrm{BT} 35^{\circ}$ ), and also the number of patients with a curve size of $50^{\circ}$ or more was

Table 2 Characteristics of 106 patients, treated for idiopathic scoliosis with onset before the age of 10 years, in terms of demographic data, the scoliotic curve and its treatment, and pulmonary function

\begin{tabular}{|c|c|c|c|c|}
\hline & All $(n=106)$ & Brace treated $(n=57)$ & $\begin{array}{l}\text { Surgically treated } \\
(n=49)\end{array}$ & $\begin{array}{l}P \text { value: } \\
\text { brace vs. } \\
\text { surgery }\end{array}$ \\
\hline Gender female & $87(82)$ & $49(86)$ & $38(78)$ & N.s. \\
\hline \multicolumn{5}{|l|}{ At time for treatment } \\
\hline \multicolumn{5}{|l|}{ Age at } \\
\hline Diagnosis, years & $\begin{array}{l}7.0(2.2) \\
0.08-9.8\end{array}$ & $\begin{array}{l}7.2(1.8) \\
0.5-9.7\end{array}$ & $\begin{array}{l}6.8(2.7) \\
0.08-9.8\end{array}$ & N.s. \\
\hline Start of treatment, years & $\begin{array}{l}12.1(2.8) \\
2.8-17.5\end{array}$ & $\begin{array}{l}10.9(2.8) \\
2.8-17.1\end{array}$ & $\begin{array}{l}13.5(2) \\
8.2-17.5\end{array}$ & $<0.001$ \\
\hline End of treatment, years & $\begin{array}{l}14.7(2.1) \\
8.5-19.1\end{array}$ & $\begin{array}{l}15.3(1.8) \\
8.5-19.1\end{array}$ & $\begin{array}{l}14.0(2.1) \\
9.8-18.5\end{array}$ & $<0.001$ \\
\hline Curve size at start of treatment, ${ }^{\circ}$ & $\begin{array}{l}42.1(18.1) \\
10-97\end{array}$ & $\begin{array}{l}28.5(8.6) \\
10-47\end{array}$ & $\begin{array}{l}57.4(13.1) \\
35-97\end{array}$ & $<0.001$ \\
\hline No of patients with curve size $\geq 50^{\circ}$ & 35 & 0 & 35 & - \\
\hline \multicolumn{5}{|l|}{ At follow-up (present study) } \\
\hline Age, years & $\begin{array}{l}41.7(7.2) \\
28.3-61.8\end{array}$ & $\begin{array}{l}41.0(6.8) \\
28.5-61.8\end{array}$ & $\begin{array}{l}42.4(7.6) \\
28.3-55.8\end{array}$ & N.s. \\
\hline $\begin{array}{l}\text { Follow-up time from completed treatment until } \\
\text { present follow-up, years }\end{array}$ & $\begin{array}{l}26.5(7.4) \\
10.5-42.1\end{array}$ & $\begin{array}{l}24.9(6.2) \\
10.5-35.0\end{array}$ & $\begin{array}{l}28.4(8.2) \\
12.1-42.1\end{array}$ & 0.011 \\
\hline Curve size at present follow-up, ${ }^{\circ} \mathrm{Cobb}$ & $\begin{array}{l}35.8(15.6) \\
4-83\end{array}$ & $\begin{array}{l}35.1(17.3) \\
4-83\end{array}$ & $\begin{array}{l}36.6(13.5) \\
15-73\end{array}$ & N.s. \\
\hline No. of patients with curve size $\geq 50^{\circ}$ & 22 & 12 & 10 & N.s. \\
\hline Trunk deformity, $^{\circ}$ (Bunell scoliometer) & $\begin{array}{l}13.4(6.2) \\
3-30\end{array}$ & $\begin{array}{l}10.7(4) \\
3-20\end{array}$ & $\begin{array}{l}16.5(6.9) \\
6-30\end{array}$ & $<0.001$ \\
\hline \multicolumn{5}{|l|}{ Pulmonary function tests } \\
\hline TLC ( $\%$ of pred. values) & $\begin{array}{l}90.0(14.6) \\
38.5-121.3\end{array}$ & $\begin{array}{l}95.6(10.5) \\
75.7-121.3\end{array}$ & $\begin{array}{l}83.8(16) \\
38.5-114.3\end{array}$ & $<0.001$ \\
\hline FVC ( $\%$ of pred. values) & $\begin{array}{l}86.0(14.6) \\
36-119\end{array}$ & $\begin{array}{l}90.8(11.5) \\
68.8-114\end{array}$ & $\begin{array}{l}80.4(15.9) \\
36-119\end{array}$ & $<0.001$ \\
\hline $\mathrm{FEV}_{1}$ (\% of pred. values) & $\begin{array}{l}88.3(17.2) \\
31.6-135.8\end{array}$ & $\begin{array}{l}95.2(12.6) \\
72.1-135.8\end{array}$ & $\begin{array}{l}80.1(18.5) \\
31.6-129.2\end{array}$ & $<0.001$ \\
\hline Ever smoker (current or ex-smoker) & $41(39 \%)$ & $24(42 \%)$ & $17(35 \%)$ & N.s. \\
\hline
\end{tabular}

Values are mean (SD) and range, or $n(\%)$

$F E V_{l}$ forced expiratory volume in one second, $F V C$ forced vital capacity, n.s. nonsignificant, $T L C$ total lung capacity, pred. predicted 
similar (ST 10 patients, BT 12 patients). The mean duration of brace treatment was 4.4 years.

At the present follow-up, operated patients had a larger trunk deformity, $16^{\circ}$, compared with the braced patients, $11^{\circ}$ $(p<0.001)$. Curve apex at present follow-up was located at T9 or above in $86(81 \%)$ of the patients.

Results concerning pulmonary function are also given in Table 2 . The mean TLC ( $\%$ predicted values) was $90 \%$, but with a large individual variation (range 38-121\%). The TLC differed significantly between the BT and ST groups with $96 \%$ and $84 \%$, respectively, $p<0.001$. Thirty-nine percent were ever-smokers, that is, current or ex-smokers, $42 \%$ of BT and 35\% of ST (nonsignificant).

\section{Thoracic mobility}

The range of motion of the thoracic spine, presented in Table 3, showed that the BT group had significantly better range of motion $(p<0.001)$, and the ST group had significantly reduced values $(p<0.001)$ compared with the reference values. The ST group had a significantly stiffer thoracic spine than the BT group $(p<0.001)$.

Both the BT and ST patients were able to expand their chest cage ("thorax expansion") significantly less (14 and $19 \mathrm{~mm}$ ) at the level of the xiphoid process, compared with the reference values $(p<0.001)$. The BT patients and the ST patients did not differ significantly, neither at the level of the xiphoid process $(p=0.07)$ nor at the level of the fourth rib $(p=0.53)$ (Table 3).

The respiratory movements (the RMMI tests) during maximal breathing, compared with a reference group of 100 healthy men and women 20-69 years of age [27], were significantly decreased, by mean values of up to $12 \mathrm{~mm}$, in both BT and ST groups, at all locations of the rib cage, compared with the reference values $(p<0.001$; Table 3$)$. There were no significant differences between the BT and ST groups (not presented in the table).

Table 3 Thoracic range of motion, thorax expansion, maximal breathing movements, and respiratory muscle strength in both groups and reference/comparison values

\begin{tabular}{|c|c|c|c|c|c|c|}
\hline & \multicolumn{3}{|l|}{$\mathrm{BT}(n=57)$} & \multicolumn{3}{|l|}{$\mathrm{ST}(n=49)$} \\
\hline & Measured value & Reference value & $P$ value & Measured value & Reference value & $P$ value \\
\hline $\begin{array}{l}\text { Thoracic range of } \\
\text { motion, kyphom- } \\
\text { eter, }^{\circ}\end{array}$ & $\begin{array}{l}39.7(8.9) \\
23.0-62.0\end{array}$ & $28.2(8.2)$ & $<0.001$ & $15.2(8.1) 0-37.0$ & $28.2(8.2)$ & $<0.001$ \\
\hline \multicolumn{7}{|l|}{ Thorax expansion, mm } \\
\hline Xiphoid process & 46.8 (19.4) 10.0-90.0 & $60.4(0.5)$ & $<0.001$ & 39.8 (19.1) 5.0-80.0 & $59.1(0.7)$ & $<0.001$ \\
\hline Fourth rib & 41.8 (17.4) 10.0-100.0 & - & - & 39.5 (17.8) 10.0-90.0 & - & - \\
\hline \multicolumn{7}{|l|}{$\begin{array}{c}\text { Maximal breathing } \\
\text { movements, } \mathrm{mm}\end{array}$} \\
\hline $\begin{array}{l}\text { Upper thoracic } \\
\text { convex }\end{array}$ & $\begin{array}{l}7.32(7.52) \\
1.23-45.72\end{array}$ & $17.69(0.03)$ & $<0.001$ & 7.54 (7.16) $0.94-38.74$ & $17.68(0.34)$ & $<0.001$ \\
\hline $\begin{array}{l}\text { Upper thoracic } \\
\text { concave }\end{array}$ & $\begin{array}{l}7.07(7.85) \\
1.14-49.21\end{array}$ & $18.09(0.16)$ & $<0.001$ & 7.16 (7.19) 0.86-36.59 & $18.11(0.14)$ & $<0.001$ \\
\hline $\begin{array}{l}\text { Lower thoracic } \\
\text { convex }\end{array}$ & $\begin{array}{l}5.32(5.29) \\
0.72-33.25\end{array}$ & $16.84(1.56)$ & $<0.001$ & 5.65 (6.57) 1.31-33.10 & $17.22(1.87)$ & $<0.001$ \\
\hline $\begin{array}{l}\text { Lower thoracic } \\
\text { concave }\end{array}$ & $\begin{array}{l}5.33(6.26) \\
0.66-41.66\end{array}$ & $16.53(1.30)$ & $<0.001$ & 5.73 (5.40) 1.48-28.24 & $16.84(1.56)$ & $<0.001$ \\
\hline Abdominal convex & $\begin{array}{l}9.18(8.54) \\
1.55-41.60\end{array}$ & $18.25(2.58)$ & $<0.001$ & 8.57 (5.95) 1.68-25.15 & $18.87(3.10)$ & $<0.001$ \\
\hline Abdominal concave & $\begin{array}{l}8.54(8.94) \\
1.04-44.70\end{array}$ & $18.52(2.50)$ & $<0.001$ & 7.89 (5.79) 1.40-27.75 & $19.13(3.02)$ & $<0.001$ \\
\hline $\begin{array}{l}\text { Respiratory muscle } \\
\text { strength, } \mathrm{cmH}_{2} \mathrm{O}\end{array}$ & $\begin{array}{l}\text { Measured value } \\
\text { BT }(n=16)\end{array}$ & $\begin{array}{l}\text { Comparison group } \\
(n=40)\end{array}$ & $p$ value & $\begin{array}{l}\text { Measured value } \\
\text { ST }(n=17)\end{array}$ & $\begin{array}{l}\text { Comparison group } \\
(n=40)\end{array}$ & $p$ value \\
\hline MIP & 78.1 (32.6) 9.0-123.0 & 88.7 (28.6) 23.0-147.0 & N.s. & 59.3 (23.4) 22.0-103.0 & 88.7 (28.6) 23.0-147.0 & $p=0.001$ \\
\hline MEP & $\begin{array}{l}112.8(34.4) 39.0- \\
169.0\end{array}$ & $\begin{array}{l}118.4(29.8) 61.0- \\
195.0\end{array}$ & N.s. & 94.2 (28.1) 57.0-149.0 & $\begin{array}{l}118.4(29.8) 61.0- \\
195.0\end{array}$ & $p=0.007$ \\
\hline
\end{tabular}

Breathing movements were adjusted to the direction of the scoliosis. Values are mean (SD) and range

$B T$ brace-treated, $M E P$ maximal expiratory pressure, $M I P$ maximal inspiratory pressure, $S T$ surgically treated 


\section{Respiratory muscle strength}

The respiratory muscle strength was significantly reduced to $67 \%$ of MIP and $79 \%$ of MEP reference values in the ST group, but this was not found for the BT group (Table 3). Between the two treatment groups, there were no significant differences in either MIP or MEP.

\section{Correlations between mobility of the thoracic spine, pulmonary function, and rib-cage deformity}

Correlation analyses between the three modes for measurement of thoracic mobility, pulmonary function, and rib-cage deformity are presented in Table 4.

The ability to expand the thorax (expansion tests) correlated little or moderately with the pulmonary function tests (TLC, FVC, and $\mathrm{FEV}_{1}$ ), $r=0.43-0.64$. Neither pulmonary function (TLC, FVC, or FEV $_{1}$ ) nor curve (size and trunk deformity) correlated with breathing movements.

Respiratory muscle strength (both MIP and MEP) correlated moderately with all the three pulmonary function

Table 4 Univariate correlations between measurements of thoracic mobility versus pulmonary function and rib-cage deformity

\begin{tabular}{lllllll}
\hline & Thor ROM* & Thor Exp upper & Thor Exp lower & $\begin{array}{l}\text { Thor Exp } \\
\text { upper+lower }\end{array}$ & $\begin{array}{l}\text { RMMI (sum of upper, lower, } \\
\text { and abdomen left and right) }\end{array}$ & $\begin{array}{l}\text { RMI (sum of upper and } \\
\text { abdomen left and right) }\end{array}$ \\
\hline TLC & 0.173 & $0.545^{* *}$ & $0.434^{* *}$ & $0.494^{* *}$ & 0.076 & 0.113 \\
FVC & $0.250^{*}$ & $0.639^{* *}$ & $0.501^{* *}$ & $0.577^{* *}$ & 0.092 & 0.131 \\
FEV $_{1}$ & $0.226^{*}$ & $0.574^{* *}$ & $0.428^{* *}$ & $0.504^{* *}$ & 0.121 & 0.163 \\
Curve size FU & 0.095 & 0.145 & 0.080 & 0.097 & 0.024 & 0.043 \\
Trunk deformity & $0.326^{* *}$ & 0.041 & 0.056 & 0.062 & 0.119 & 0.127 \\
\hline
\end{tabular}

$\mathrm{FEV}_{1}$, forced expiratory volume in one second; FVC, forced vital capacity; RMMI, Respiratory Movement Measuring Instrument; TLC, total lung capacity

*Thoracic range of motion (kyphometer)

${ }^{\dagger}$ Thorax expansion at the level of the fourth rib

${ }^{\ddagger}$ Thorax expansion at the level of the xiphoid process

${ }^{\S}$ Thorax expansion, the sum of upper and lower

${ }^{*} p \leq 0.05, * * p \leq 0.01$

Table 5 Univariate correlations between MIP and MEP versus thorax expansion and pulmonary function
Table 6 Multivariate analysis for explaining TLC percentage predicted and based on significant results of the univariable analyses revealed the following variables and beta values

\begin{tabular}{lllllll}
\hline & TLC & FVC & FEV $_{1}$ & Thorax exp upper* & Thorax exp lower $\dagger$ & $\begin{array}{l}\text { Thorax exp } \\
\text { upper + lower }\end{array}$ \\
\hline MIP & $0.504^{* *}$ & $0.529^{* *}$ & $0.568^{* *}$ & $0.530^{* *}$ & $0.408^{*}$ & $0.525^{* *}$ \\
MEP & $0.574^{* *}$ & $0.567^{* *}$ & $0.605^{* *}$ & $0.611^{* *}$ & $0.553^{* *}$ & $0.631^{* *}$ \\
\hline
\end{tabular}

$F E V_{1}$ forced expiratory volume in one second, $F V C$ forced vital capacity, MEP maximal expiratory pressure, $M I P$ maximal inspiratory pressure, $T L C$ total lung capacity

*Thorax expansion at the level of the fourth rib

${ }^{\dagger}$ Thorax expansion at the level of the xiphoid process

Thorax expansion, the sum of upper and lower

$* p \leq 0.05, * * p \leq 0.01$

\begin{tabular}{lll}
\hline & Univariable & Multivariable \\
\hline${\text { Curve size at start of treatment, }{ }^{\circ}}^{\circ}$ & $-0.53(p<.0 .001)$ & $-0.21(p=0.016)$ \\
Thorax expansion, xiphoideus, cm & $3.32(p<0.0001$ & $3.00(p<0.0001)$ \\
Gender, male or female & $8.98(p=0.014)$ & $13.59(p<0.0001)$ \\
Brace model, Milwaukee or Boston & $10.21(p<0.0007)$ & $5.50(p=0.018)$ \\
Smoking habits, never or ever-smokers & $10.40(p=0.0003)$ & $6.25(p=0.010)$ \\
\hline
\end{tabular}


tests, TLC, FVC, and $\mathrm{FEV}_{1}(r=0.50-0.61)$, as well as with thorax expansion (upper, lower, and upper in combination with lower) $(r=0.41-0.63)$ (Table 5).

\section{Multivariate analysis}

A multivariable linear regression model explaining TLC as percentage of predicted was based on significant results of the univariable analysis and results are presented in Table 6. The $R$-squared value for the multivariable model was 0.619 .

An additional analysis was made for the subgroup of 33 patients, who were also examined for respiratory muscle strength. These added variables were not strong enough to further explain the percentage of TLC predicted.

\section{Discussion}

This study is the first follow-up of thoracic mobility in previously treated patients with early onset idiopathic scoliosis. The main finding is that both brace-treated and surgically treated patients showed significantly reduced thorax expansion and respiratory movements at a mean of 26.5 years after completed treatment. Our aim was to explore these findings in relation to the pulmonary function, which were previously presented (https://doi.org/10.1016/j.jspd.2015.07.007).

\section{Thoracic mobility}

The range of motion of the thoracic spine was measured with a Debrunner Kyphometer and, as expected, the ST group had significantly reduced values compared with the BT group as a result of several fused vertebrae, as in previous studies of adolescent idiopathic scoliosis [5]. The ability for the chest cage to expand the thorax was significantly reduced by $14-19 \mathrm{~mm}$ in both groups, compared with the reference values. Two other studies have previously, with other methods, evaluated rib-cage movements in patients with idiopathic scoliosis and found them to be reduced [32, 33]. As information about onset of scoliosis or treatment is lacking in those studies, comparisons are troublesome. The clinical value of the reduction, being less than $20 \mathrm{~mm}$, needs to be established before a proper evaluation on pulmonary function can be made.

Maximal breathing movements during deep breathing were measured with RMMI, and the patients had approximately $10 \mathrm{~mm}$ less movement compared with the reference values [27]. No previous studies on individuals with scoliosis exist for comparison. The reduction is likely to be considered small, in relation to the total anteroposterior diameter, and the clinical significance needs to be evaluated with further studies.

\section{Respiratory muscle strength}

The possibility for later evaluation of respiratory muscle strength led us to add this examination in a subgroup of 33 patients, as this component is considered to be of high importance for respiration. This subgroup was similar in terms of curve size and ever-smokers.

The surgically treated patients in this subgroup had significantly less muscle strength compared with the reference group, whereas the braced patients had not. In addition, the moderate correlations between respiratory muscle strength and pulmonary variables were found. Muscle strength and function are closely associated with one another and decreased thoracic mobility was found in the scoliotic patients. Whether these findings are results of the scoliotic rib-cage deformity itself or a stiffer spine after surgery or a prolonged brace treatment is unknown. This study evaluates late additive results of both deformity and the treatment of the deformity, and was not designed to evaluate these issues separately.

Respiratory muscle strength has previously been tested in patients with chronic obstructive pulmonary disease [34], cystic fibrosis [35], and ankylosing spondylitis [36] and found to have different levels of associations. In the latter study [36], they found correlations between thorax expansion and MIP and MEP, similar to our findings.

From our results, it is not possible to evaluate whether the diaphragmatic motion is affected, because we have not evaluated its function. Kotani et al. [33], who also found restricted rib-cage movements in patients with idiopathic scoliosis, reported that the diaphragmatic motion was normal. This is contradictory to Chu et al. [37], who found that diaphragmatic heights significantly reduced in patients with severe idiopathic scoliosis when measured by dynamic magnetic resonance imaging.

\section{Correlations between results}

The ability for thorax expansion and the respiratory muscle strength correlated (moderately) with the pulmonary function (TLC, FVC, and $\mathrm{FEV}_{1}$ ), whereas the breathing movements (RMMI) did not show any correlations of significance. Hagman et al. [38] found a strong correlation between measured breathing movements and breathing volumes. They did their measurements, with RMMI and a dynamic spirometer, simultaneously in three different body positions-supine, sitting on a chair, and standing with the back against a wall. In our study, the supine position was used for the breathing movements with RMMI because of the need of a stable position for the measurement of the anteroposterior movements and the fact that the reference values were collected in the supine position [27]. Both the spirometry and the respiratory muscle strength were measured in the sitting position, 
whereas the expansion of the thorax during breathing was measured in an upright standing position because of the testing position of this reference group [13]. These different body positions during the tests might be an explanation for the lack of correlation.

\section{Further comments on pulmonary function tests and smoking habits}

The ventilatory capacity of the patients in this study was evaluated by use of spirometry, with data on FVC and FEV as well as by use of body plethysmograph measuring TLC. The pulmonary function tests are presented as percentage predicted values. These are mean values for the normal population adjusted for height, age, and gender, and therefore, normal individual predicted values range from 80 to $120 \%$ [25]. The main deterioration of pulmonary function due to scoliosis and its treatment is restrictive ventilation. TLC is the key measurement to evaluate restrictive disorders of ventilation and was, therefore, chosen as the main outcome of the pulmonary function in this study.

The multivariate linear regression model, aimed to explain the TLC percentage predicted, included five variables, of which two belong to the time of the treatment (curve size and type of brace), two to demographics (gender and smoking), and one to the time of the current follow-up (lower thorax expansion). Their level of explanation was an R-squared value of 0.619 . Gender, brace model, smoking habits, thorax expansion (xiphoideus), and curve size at start of treatment were strongly associated with TLC percentage predicted.

The impact of gender in lung volumes is well-known, as men in general have larger lung volumes than women. Despite our analyses using the percentage of predicted values, constructed to eliminate the gender difference, the male gender has an association with lower TLC in this study. That the type of brace was of importance can be explained by the use of the stiffer Milwaukee brace compared with the less rigid Boston brace, which is still in use. With more modern braces in use, for instance, the night braces worn for less time, these negative effects might be reduced in the future.

Smoking has a strong association to TLC percentage predicted values, where "ever-smokers" have higher values (96\% of predicted) than never-smokers ( $86 \%$ of predicted). This finding presents a possible difficulty in evaluating the effect on the decrease of TLC related to treatment for scoliosis. The higher values in smokers is most probably due to the development of emphysema, which also has been reported to increase TLC in apparently healthy smokers [39]. As the proportion of smokers does not differ between the surgically or brace-treated groups, our interpretation is that smoking does not influence the effect of various treatments for scoliosis, where increasing curve size or decreasing thoracic expansion is related to a low TLC, as a matter of restrictive pulmonary function. Emphysema adds an obstructive component to any restrictive consequence of scoliosis; therefore, avoiding or quitting smoking is a very important advice for patients treated for scoliosis.

\section{Strength and limitations of the study}

One advantage of this study is the long follow-up time of a group of 106 patients with early onset scoliosis. The original group of 179 patients is considered a consecutive series of which finally $59 \%$ participated. Another advantage is that we have analyzed the mobility of the thoracic cage and its relation to the total lung capacity, which has previously not been studied. A limitation of the study is that we did not compare the results to matched control subjects. To compensate, we used reference values consisting of corresponding groups of healthy individuals of similar age and gender. Another limitation is that the number of patients in the subgroup having measured MIP and MEP is small. However, both brace-treated and surgically treated were evaluated together.

\section{Conclusions}

Thoracic mobility was significantly reduced at follow-up (mean 26.5 years after completed treatment) in both bracetreated and surgically treated patients with early onset scoliosis. TLC values as a measurement of pulmonary function were influenced by gender, brace model, smoking habits, thorax expansion, and curve size at the start of treatment. Because smoking is also associated with several additional health problems, patients must be advised to not smoke.

\section{Key points}

- Thoracic mobility, except for the range of motion of the thoracic spine in the brace-treated patients, was significantly reduced at mean 26.5 years after completed treatment.

- These reductions had limited impact on the total lung capacity.

- The total lung capacity had strong associations with smoking habits, brace model, gender, thorax expansion (xiphoideus), and curve size at the start of treatment.

- Individuals with scoliosis must be strongly advised not to smoke.

Acknowledgements Open access funding provided by University of Gothenburg. We wish to thank Anne Dohsé, RN, Department of 
Orthopaedics, Gothenburg University, for assistance during the study. We would also like to thank Kate Bramley-Moore, PhD, for her English language editing assistance.

Funding Funds were received as total or partial support for the research in this article from the Gothenburg Medical Society, the Neubergh Foundations, and through "the Agreement concerning research and education of doctors", the Renée Eander fund and the Norrbacka Eugenia fund. No benefits in any form have been received or will be received from a commercial party related directly or indirectly to the subject of this article.

\section{Compliance with ethical standards}

Conflict of interest KR (none), MFO (none), GKW (none), KLH (none), $\mathrm{AD}$ (none).

IRB approval The study was approved by the Human Research Committee at the Medical Faculty, Gothenburg University, Gothenburg, Sweden, \# 081/07. The patients were included after verbal and written information and signed consent.

Open Access This article is licensed under a Creative Commons Attribution 4.0 International License, which permits use, sharing, adaptation, distribution and reproduction in any medium or format, as long as you give appropriate credit to the original author(s) and the source, provide a link to the Creative Commons licence, and indicate if changes were made. The images or other third party material in this article are included in the article's Creative Commons licence, unless indicated otherwise in a credit line to the material. If material is not included in the article's Creative Commons licence and your intended use is not permitted by statutory regulation or exceeds the permitted use, you will need to obtain permission directly from the copyright holder. To view a copy of this licence, visit http://creativecommons.org/licenses/by/4.0/.

\section{References}

1. Pehrsson K, Larsson S, Oden A, Nachemson A (1992) Long-term follow-up of patients with untreated scoliosis. A study of mortality, causes of death, and symptoms. Spine 17:1091-1096

2. Davies G, Reid L (1970) Growth of the alveoli and pulmonary arteries in childhood. Thorax 25:669-681

3. Narayanan M, Owers-Bradley J, Beardsmore CS et al (2012) Alveolarization continues during childhood and adolescence: new evidence from helium-3 magnetic resonance. Am J Respir Crit Care Med 185:186-191

4. Charles YP, Dimeglio A, Marcoul M et al (2008) Influence of idiopathic scoliosis on three-dimensional thoracic growth. Spine (Phila Pa 1976) 33:1209-1218

5. Danielsson AJ, Romberg K, Nachemson AL (2006) Spinal range of motion, muscle endurance, and back pain and function at least 20 years after fusion or brace treatment for adolescent idiopathic scoliosis: a case-control study. Spine (Phila Pa 1976) 31:275-283

6. Grauers A, Topalis C, Moller H et al (2014) Prevalence of back problems in 1069 adults with idiopathic scoliosis and 158 adults without scoliosis. Spine (Phila Pa 1976) 39:886-892

7. Mahaudens P, Banse X, Mousny M et al (2013) Very short-term effect of brace wearing on gait in adolescent idiopathic scoliosis girls. Eur Spine J 22:2399-2406

8. Quanjer PH, Stanojevic S, Cole TJ et al (2012) Multi-ethnic reference values for spirometry for the 3-95-years age range: the global lung function 2012 equations. Eur Respir J 40:1324-1343
9. Konno K, Mead J (1967) Measurement of the separate volume changes of rib cage and abdomen during breathing. J Appl Physiol 22:407-422

10. Lumb AB, Nunn JF (1991) Respiratory function and ribcage contribution to ventilation in body positions commonly used during anesthesia. Anesth Analg 73:422-426

11. Öhlén G (1989) Spinal sagittal configuration and mobility: a kyphometer study

12. Moll JM, Wright V (1972) An objective clinical study of chest expansion. Ann Rheum Dis 31:1-8

13. Finsbäck C, Mannerkorpi K (2005) Spinal and thoracic mobilityage-related values for healthy men and women. Nord Fysioter 9:136-143

14. Olsén MF, Lindstrand H, Broberg JL, Westerdahl E (2011) Measuring chest expansion: a study comparing two different instructions. Adv Physiother 13:128-132

15. Banzett RB, Mahan ST, Garner DM et al (1985) A simple and reliable method to calibrate respiratory magnetometers and respitrace. J Appl Physiol 1995(79):2169-2176

16. Agostoni E, Rahn H (1960) Abdominal and thoracic pressures at different lung volumes. J Appl Physiol 15:1087-1092

17. Cohn M, Watson H, Weisshaut R et al (eds) (1978) A transducer for non-invasive monitoring of respiration. Proceedings of the Second International Symposium on Ambulatory Monitoring. New York, NY: Academic Press

18. Ragnarsdottir M, Geirsson AJ, Gudbjornsson B (2008) Rib cage motion in ankylosing spondylitis patients: a pilot study. Spine J 8:505-509

19. Kristjansdottir A, Ragnarsdottir M, Hannesson P et al (2004) Respiratory movements are altered 3 months and 1 year following cardiac surgery. Scand Cardiovasc J 38:98-103

20. Johansson EL, Ternesten-Hasseus E, Olsen MF, Millqvist E (2012) Respiratory movement and pain thresholds in airway environmental sensitivity, asthma and COPD. Respir Med 106:1006-1013

21. Rochester DF (1985) The diaphragm: contractile properties and fatigue. J Clin Invest 75:1397-1402

22. Sclauser Pessoa IM, Franco Parreira V, Fregonezi GA et al (2014) Reference values for maximal inspiratory pressure: a systematic review. Can Respir J 21:43-50

23. Amendt LE, Ause-Ellias KL, Eybers JL et al (1990) Validity and reliability testing of the scoliometer. Phys Ther 70:108-117

24. Cobb J (1948) Technique for study of scoliosis. AAOS Instructional course lectures. pp 261-75

25. Quanjer PH, Tammeling GJ, Cotes JE et al (1993) Lung volumes and forced ventilatory flows. Eur Respir J 6(suppl 16):5-40

26. Lindh M, Bjure J (1975) Lung volumes in scoliosis before and after correction by the Harrington instrumentation method. Acta Orthop Scand 46:934-948

27. Ragnarsdottir M, Kristinsdottir EK (2006) Breathing movements and breathing patterns among healthy men and women 20-69 years of age. Reference values. Respiration 73:48-54

28. Cahalin LP, Ragnarsdottir M (2002) Reliability, validity, and clinical utility of a novel respiratory movement measurement instrument (critical care-outcomes: 12: 00 pm-1: 45 pm). Chest 122:207

29. Gunnesson IL, Olsen MF (2011) Validity in measuring breathing movements with the respiratory movement measuring instrument, RMMI. Clin Physiol Funct Imaging 31:1-4

30. Olsen MF, Romberg K (2010) Reliability of the respiratory movement measuring instrument, RMMI. Clin Physiol Funct Imaging 30:349-353

31. Domholdt E (2005) Rehabilitation research: principles and applications. Elsevier Saunders, St. Louis 
32. Leong J, Lu W, Luk K, Karlberg E (1999) Kinematics of the chest cage and spine during breathing in healthy individuals and in patients with adolescent idiopathic scoliosis. Spine 24:1310

33. Kotani T, Minami S, Takahashi K et al (2004) An analysis of chest wall and diaphragm motions in patients with idiopathic scoliosis using dynamic breathing MRI. Spine 29:298-302

34. Kim NS, Seo JH, Ko MH et al (2017) Respiratory muscle strength in patients with chronic obstructive pulmonary disease. Ann Rehabil Med 41:659-666

35. Arikan H, Yatar I, Calik-Kutukcu E et al (2015) A comparison of respiratory and peripheral muscle strength, functional exercise capacity, activities of daily living and physical fitness in patients with cystic fibrosis and healthy subjects. Res Dev Disabil 45(46):147-156

36. Sahin G, Calikoglu M, Ozge C et al (2004) Respiratory muscle strength but not BASFI score relates to diminished chest expansion in ankylosing spondylitis. Clin Rheumatol 23:199-202
37. Chu WC, Li AM, Ng BK et al (2006) Dynamic magnetic resonance imaging in assessing lung volumes, chest wall, and diaphragm motions in adolescent idiopathic scoliosis versus normal controls. Spine 31:2243-2249

38. Hagman C, Janson C, Malinovschi A et al (2016) Measuring breathing patterns and respiratory movements with the respiratory movement measuring instrument. Clin Physiol Funct Imaging $36: 414-420$

39. Tylen U, Boijsen M, Ekberg-Jansson A et al (2000) Emphysematous lesions and lung function in healthy smokers 60 years of age. Respir Med 94:38-43

Publisher's Note Springer Nature remains neutral with regard to jurisdictional claims in published maps and institutional affiliations. 